\title{
Our Surgical Experience in Chronic Pancreatitis
}

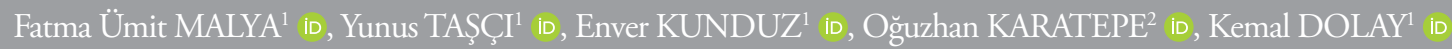

\section{${ }^{1}$ Department of General Surgery, Bezmialem Vakif University School of Medicine, İstanbul, Turkey}

${ }^{2}$ Department of General Surgery, Memorial Hospital, İstanbul, Turkey

\section{ABSTRACT}

Objective: Chronic pancreatitis is an inflammatory disease that causes progressive destruction of the pancreas and is characterized by recurrent abdominal pain. Various surgical procedures have been identified to treat this disease. In this study, we aimed to present our experience in a variety of surgical indications in patients with chronic pancreatitis.

Methods: Between December 2012 and January 2016, eight patients underwent surgery for chronic pancreatitis in our clinic. The etiology of chronic pancreatitis, implementation of the operation with surgical indications, mortality, morbidity, and clinical outcomes were assessed.

Results: Of the patients included in the study, two were females and six were males. The average age of the patients was 41.7 years (range, 20-62 years). Two patients had chronic pancreatitis due to autoimmune pancreatitis. Beger procedure was performed for these patients. In three patients with idiopathic chronic pancreatitis, the pancreatic duct was severely dilated and there were widespread stones along the pancreatic canal. These patients underwent modified Puestow pancreaticojejunostomy. One patient who had severe abdominal pain was treated with Whipple procedure and an other patient with total pancreatectomy. One patient who had a suspected mass on pancreatic head was treated with Whipple procedure. Surgical wound infection developed in one patient. No cases of mortality was observed. Nearly complete pain relief was observed in postoperative short-time follow-up period.

Conclusion: Chronic pancreatitis is a rarely observed disease, which requires long-term and multidisciplinary follow-up. In selective cases, appropriate surgical procedures may provide an effective treatment option with low mortality and morbidity rates.

Keywords: Chronic pancreatitis, multidisciplinary follow-up, surgery

\section{Introduction}

Chronic pancreatitis (CP) is an irreversible inflammatory process. It is characterized by the progressive fibrosis of the pancreas. It can result in abdominal pain, exocrine failure, and diabetes mellitus (1). The incidence rate of CP is approximately 5-10 per 100,000 individuals (2). Alcohol, hypercalcemia, morphological differences (pancreas divisum), hereditary diseases (cystic fibrosis), and immunological factors (viral infections) play a role in its etiology. In the absence of any factor, $\mathrm{CP}$ can be defined as idiopathic (3).

The appropriate treatment approach to $\mathrm{CP}$ is controversial. However, there are main principles in its treatment approach. The basic approach includes relieving the present pain and treating possible organ complications. A multidisciplinary approach is required in the selection of patients. Age, anamnesis, physical state, condition causing the disease, and accompanying complications should be considered. The most important indication for surgical intervention is uncontrolled pain originating from the pancreas. In addition, surgical procedures for complications developing in adjacent organs can be performed. These complications include obstructions in the distal choledoch, segmental duodenal obstruction, uncontrolled permanent pseudocysts with ductal pathology, and pancreatic fistulas that cannot be treated conservatively.

Cite this article as: Malya FÜ, Taş̧̧ı Y, Kunduz E, Karatepe O, Dolay K. Our Surgical Experience in Chronic Pancreatitis. Bezmialem Science 2018; 6: 15-20. 
Moreover, suspect of malignancy that cannot be eliminated through imaging and diagnostic techniques is another indication (3).

The cause of CP-associated pain has been demonstrated to be pancreatic ductal and parenchymal hypertension and perineural inflammatory changes. For the treatment to be effective, the main purpose of both endoscopic and surgical treatments is to decrease pressure by providing the drainage of the pancreatic duct $(2,3)$.

Surgical treatment is planned by taking into consideration the preoperative findings of computed tomography, magnetic

Table 1. Demographic data, symptoms, findings, and histories of cases.

\begin{tabular}{l|c} 
Demographic data & Year \\
\hline Age & $20-62$ \\
Mean age & 41.7 \\
Gender & $\mathrm{N}(\%)$ \\
Male & $6(75)$ \\
Female & $2(25)$ \\
Symptoms and findings & No. of cases (\%) \\
Abdominal pain & $8(100)$ \\
Jaundice & $2(25)$ \\
Nausea and vomiting & $2(25)$ \\
Weight loss & $5(62.5)$ \\
Diarrhea & $2(25)$ \\
History & $\mathrm{N}(\%)$ \\
Diabetes mellitus & $2(25)$ \\
Hypertension & $1(12.5)$ \\
Coronary artery disease & $1(12.5)$ \\
Cardiac arrhythmia & $1(12.5)$
\end{tabular}

resonance imaging, and endoscopic retrograde cholangiopancreatography. The aim of the present study was to present our surgical experience in cases with $\mathrm{CP}$ with various indications.

\section{Methods}

A total of eight patients were operated due to $\mathrm{CP}$ in our clinic between December 2015 and January 2016. Patients' demographic data, medical histories, symptoms at admission, duration of hospitalization, short-term survival, etiology of the disease, diagnostic methods, surgical indications, surgical procedures that were applied, and results of these procedures were evaluated retrospectively. Beger procedure, pancreaticoduodenectomy, pylorus-preserving pancreaticoduodenectomy, and total pancreatectomy were the surgical resection procedures that were performed. On the other hand, Puestow and modified Puestow (Partington) were the drainage procedures. Postoperative occurrences of wound site infection, cardiac complications, and pancreatic fistula were evaluated as morbidity, whereas surgical outcomes were recorded as decreased pain after surgery, diabetes mellitus, diarrhea, and steatorrhea. The study was conducted in accordance with the ethical standards of the principles of the Declaration of Helsinki.

\section{Statistical analysis}

All statistical analyses were measured by using the Statistical Package for the Social Sciences for Windows version 11.0 (SPSS Inc., Chicago, IL, USA). The results were expressed as mean \pm standard deviation.

\section{Results}

Of the eight patients included in the study, two were females, and six were males. The mean age of the patients was 41.7 (20-62) years. Table 1 shows the demographic data of the patients. CP developed in two patients due to autoimmune pancreatitis. These two patients had pain and weight loss. Beger surgery was performed in them. In three patients with idiopathic CP, severely dilated pancreatic duct and diffuse stones

Table 2. Surgeries performed according to indications.

\begin{tabular}{|c|c|}
\hline Patients & Indications \\
\hline Patient 1 & Autoimmune pancreatitis \\
\hline Patient 2 & Autoimmune pancreatitis \\
\hline Patient 3 & Idiopathic pancreatitis \\
\hline Patient 4 & Idiopathic pancreatitis \\
\hline Patient 5 & Idiopathic pancreatitis \\
\hline Patient 6 & Idiopathic pancreatitis \\
\hline Patient 7 & Alcoholic pancreatitis \\
\hline Patient 8 & Idiopathic pancreatitis \\
\hline
\end{tabular}

\section{Accompanying symptoms}

Pain, weight loss

Pain, weight loss

Pain, dilated pancreatic duct, and diffuse stones along the distal pancreas

Pain, weight loss, dilated pancreatic duct, and diffuse stones along the distal pancreas

Pain, weight loss, dilated pancreatic duct, and diffuse stones along the distal pancreas

Pain, nausea, vomiting, jaundice, weight loss

Pain, nausea, vomiting, jaundice, weight loss

Pain, nausea, vomiting, jaundice, suspected malignancy on the head of the pancreas

\section{Surgery}

Beger

Beger

Partington

Partington

Partington

Whipple

Total pancreatectomy

Whipple 


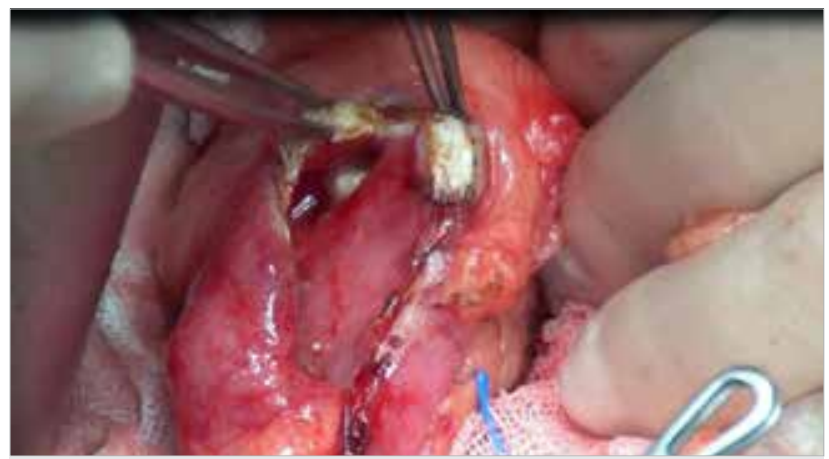

Figure 1. Removal of diffuse stones in the dilated pancreatic duct

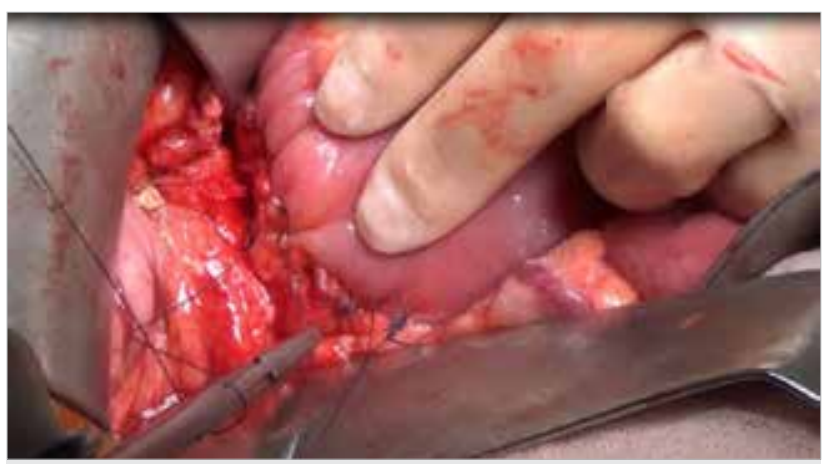

Figure 2. Modified Puestow (Partington) surgery. View of side-to-side pancreaticojejunostomy

along the duct were observed (Fig. 1). These patients in which endoscopic treatments failed underwent modified Puestow pancreaticojejunostomy (Partington) (Fig. 2). One out of two patients who had severe pain and had no response to medical therapy underwent the Whipple procedure, and the other one was applied total pancreatectomy. These patients also had complaints of nausea, vomiting, and jaundice. In one patient who had chronic pain and suspected malignancy on the head of the pancreas, the Whipple procedure was performed, and no malignancy was found. Table 2 shows the surgeries performed according to indications. All patients planned to undergo a surgical procedure were evaluated in terms of possible gastrointestinal malignancy and chronic liver disease preoperatively (endoscopy, colonoscopy, liver function tests, and hepatitis markers). All patients followed up due to complaint of chronic pain were evaluated for surgery after a long-term narcotic analgesic therapy under the supervision of the Algology Department. These therapies were not successful in one patient; therefore, celiac ganglion block was endoscopically performed. Despite short-term regression in pain after this treatment, pain complaint of the patient recurred in the follow-ups. Postoperative wound site infection developed in one patient undergoing pancreaticoduodenectomy. There was no mortality observed. Regression in pain was detected in four out of five patients undergoing resection after surgery and in all of three patients undergoing drainage. In one patient who
Table 3. Surgical results.

\begin{tabular}{|c|c|}
\hline \multicolumn{2}{|c|}{ Duration of surgery (min) } \\
\hline Resection & $360(270-420)$ \\
\hline Drainage & $270(250-300)$ \\
\hline \multicolumn{2}{|c|}{ Duration of hospitalization (day) } \\
\hline Resection & $8(7-11)$ \\
\hline Drainage & $7(6-10)$ \\
\hline \multicolumn{2}{|c|}{ Intraoperative bleeding (cc) } \\
\hline Resection & $200(150-300)$ \\
\hline Drainage & $100(50-150)$ \\
\hline \multicolumn{2}{|c|}{ Wound site complications } \\
\hline Resection & 1 \\
\hline Drainage & 0 \\
\hline \multicolumn{2}{|c|}{ Pancreatic fistula } \\
\hline Resection & 0 \\
\hline Drainage & 1 \\
\hline \multicolumn{2}{|l|}{ Pain control } \\
\hline Resection & $4(\% 80)$ \\
\hline Drainage & $3(\% 100)$ \\
\hline \multicolumn{2}{|c|}{ Diabetes mellitus } \\
\hline Resection & 2 \\
\hline Drainage & 1 \\
\hline \multicolumn{2}{|c|}{ Diarrhea, steatorrhea } \\
\hline Resection & 2 \\
\hline Drainage & 0 \\
\hline
\end{tabular}

had the Beger procedure, the development of pancreatic fistula, which did not require an additional intervention, was observed. Table 3 shows the surgical data of the patients.

\section{Discussion}

There are many factors affecting the selection of surgical procedure that will be performed in CP. These include the anatomy of the pancreatic duct, its size and diameter, the spread of pancreatitis in the pancreas gland, the presence of an accompanying pseudocyst or biliary tract obstructions, and the general condition of patient. Moreover, the type of treatment is chosen based on the signs of the disease and developing complications. Two surgical procedures can be performed for the surgical treatment of $\mathrm{CP}$. These are drainage and resection. In most of the patients with CP (75\%), dilatation is observed in the pancreatic duct, allowing the application of drainage procedures. In other patients, various resection procedures can be performed. One of the procedures that are most commonly performed in patients with wide pancreatic duct is longitudinal pancreaticojejunostomy, which is a modification of the Puestow-Gillesby (Partington and Rochelle) procedure. In 
this technique, the anterior surface of the pancreas is opened, and the location of the pancreatic duct is identified. The pancreatic duct is longitudinally opened. Mud and stones inside the duct are removed. The proximal jejunum and pancreatic duct are anastomosed in Roux-en- $Y$ in two layers. On the other hand, the Puestow-Gillesby technique is performed as distal pancreatectomy, splenectomy, and longitudinal pancreaticojejunostomy. In the Duval technique, which is another drainage technique, distal pancreatectomy, splenectomy, and pancreaticojejunostomy are applied $(4,5)$.

In patients with narrow pancreatic duct, which makes conservative methods ineffective, and in the presence of suspected malignancy, procedures including resection are performed. Pancreaticoduodenectomy, pylorus-preserving pancreaticoduodenectomy, duodenum-preserving resection of the pancreatic head (Beger), and Frey procedure, in which longitudinal pancreaticojejunostomy is applied with duodenumpreserving resection of the pancreatic head, are the main techniques used $(6,7)$.

Treatment of $\mathrm{CP}$ is highly difficult and controversial. In many cases, the cause of pancreatitis is alcohol in $75 \%-90 \%$ of patients and idiopathic in $20 \%-25 \%$ of patients (8). In patients with $\mathrm{CP}$, pain that negatively affects the quality of life and that cannot medically be relieved is the most important factor that affects the decision of surgery (3). Surgery is performed due to several reasons, such as impaired quality of life, narcotic dependence, suspected malignancy, and development of $\mathrm{CP}$-associated complications. In the present study, refractory abdominal pain was the most common indication for surgery.

If malignancy is suspected in patients planned to be operated due to the prediagnosis of $\mathrm{CP}$, resective interventions are primarily considered (9). Drainage procedures are preferred for patients without any finding of malignancy but with pancreatic duct dilatation. According to the available series, surgery can be performed with reliable, acceptable mortality and morbidity rates in patients with CP. Despite increased endocrine and exocrine failures in patients, quality of life is improved, and long-term survival reaches acceptable levels after surgical intervention (10).

In cases with $\mathrm{CP}$ with dilated pancreatic duct, decompression procedures are frequently applied. In 1958, Puestow and Gillesby defined longitudinal Roux-en-Y pancreaticojejunostomy along the body and tail of the pancreas (11). In 1960, Partington and Rochelle defined lateral longitudinal pancreaticojejunostomy without resection; this procedure is known as the modified Puestow procedure (12). With this procedure, which can be applied with low mortality and morbidity rates, pain control can be obtained in $61 \%-91 \%$ of patients in a short period. However, pain recurs in approximately $30 \%$ of patients in 3-5 years. This is attributed to insufficient decom-
Pancreaticoduodenectomy is a technique that reduces pain symptoms, particularly in CP affecting the head of the pancreas. Pain control can be achieved in $71 \%-89 \%$ of patients. In addition to that, it is a procedure with high morbidity (15). Pylorus-preserving pancreaticoduodenectomy is another alternative in which postoperative diet is provided more effectively. The most important disadvantage of these methods is the occurrence of apparent impairment in pancreatic endocrine and exocrine functions with the resection of the duodenum. Total pancreatectomy is a technique that can be applied in patients with severe dysfunction and pain or with non-regression in symptoms despite other surgical procedures. A serious impairment in glucose regulation is reported to be the most important disadvantage of this technique (16).

Although resection procedures are effective in pain control, hybrid techniques have been started to be defined with the search of the protection of functions. Duodenum-preserving pancreatic head resection, which was defined by Beger in 1980, is the most commonly known and applied technique (17). With this technique, pain control can be achieved at a rate of $>80 \%$, and functional loss is also avoided (18). The Frey procedure, which was defined in 1987, is a modification of the Beger and Partington techniques. With this technique, the neck of the pancreas is preserved over the portal vein, and excessive bleeding is avoided. Moreover, drainage of the pancreatic duct can be provided in the body and tail of the pancreas (19). The Hamburg procedure, which is reported to provide pain control at a rate of $89 \%$, is also a modification of the Frey procedure (20).

Klempa et al. (21) and Buchler et al. (22) compared the classical or pylorus-preserving Whipple procedure with the Beger procedure. They reported that the Beger procedure is more successful in long-term pain control, and it can be performed with a lower morbidity rate.

In the prospective study by Izbicki et al. (23), they compared the Frey procedure and pancreaticoduodenectomy. They stated that the Frey procedure provides less morbidity, better functioning, and higher quality of life. On the other hand, pain control results were found to be similar. In another study by Izbicki et al. (24), they compared the Frey procedure and the Beger procedure. They found that long-term outcomes are similar in terms of morbidity, pain control, and quality of life.

Considering the surgeries performed in our study, it is seen that drainage and resection procedures have similar results. Pain control was also effectively obtained in two patients undergoing the Beger procedure. In one patient undergoing the Whipple procedure, pain complaint recurred after a short period. CP etiology of this patient included alcohol consumption, and alcohol addiction continued after surgery. Diabetes mellitus did not develop in any patient, except for one undergoing total pancreatectomy. 
The number of patients was limited in our study. Therefore, it was impossible to make a significant comparison among surgical procedures. Although short-term results of pain control were highly good in our study, it will be possible to make broader interpretation with the re-evaluation of patients in long-term follow-ups. Moreover, since our study was retrospective, pain scoring was not performed to objectively evaluate preoperative and postoperative pain and surgical outcomes. For this purpose, prospectively designed further studies are needed in order to obtain more objective and comparative results.

\section{Conclusion}

Chronic pancreatitis is a rarely seen condition that causes an apparent impairment in the quality of life and requires a long-term multidisciplinary follow-up. In cases for which endoscopic approaches and medical treatment are insufficient and in the presence of malignancy, appropriate surgical procedures can provide effective treatment with low mortality and morbidity. For determination of surgical approach that will be selected, preoperative detailing of pathomorphological changes in patient appears to be important for obtaining more effective results.

Ethics Committee Approval: Authors declared that the research was conducted according to the principles of the World Medical Association Declaration of Helsinki "Ethical Principles for Medical Research Involving Human Subjects”, (amended in October 2013).

Peer-review: Externally peer-reviewed.

Author Contributions: Concept - F.Ü.M., K.D.; Design - F.Ü.M.; Supervision - F.Ü.M., K.D.; Resources - F.Ü.M., O.K.; Materials F.Ü.M., O.K., K.D.; Data Collection and/or Processing - F.Ü.M., Y.T.; Analysis and/or Interpretation - E.K., F.Ü.M.; Literature Search - F.Ü.M., Y.T.; Writing Manuscript - K.D.; Critical Review - K.D.

Conflict of Interest: No conflict of interest was declared by the authors.

Financial Disclosure: The authors declared that this study has received no financial support.

\section{References}

1. Etemad B, Whitcomb DC. Chronic pancreatitis: diagnosis, classification, and new genetic developments. Gastroenterology 2001; 120: 682-707. [CrossRef]

2. Secknus R, Mössner J. Changes in incidence and prevalence of acute and chronic pancreatitis in Germany. Chirurg 2000; 71: 249-52. [CrossRef]

3. Hartel M, Tempia-Caliera AA, Wente MN, Z'graggen K, Friess $\mathrm{H}$, Büchler MW. Evidence-based surgery in chronic pancreatitis. Langenbecks Arch Surg 2003; 388: 132-9.

4. Prinz RA, Greenlee HB. Pancreatic duct drainage in chronic pancreatitis. Hepatogastroenterology 1990; 37: 295-300.

5. İzbicki JR, Bloechle C, Broering DC, Knoefel WT, Kuechler T, Broelsch CE. Extended drainage versus resection in surgery for chronic pancreatitis: a prospective randomized trial comparing the longitudinal pancreaticojejunostomy combined with local pancreatic head excision with the pylorus-preserving pancreatoduodenectomy. Ann Surg 1998; 228: 771-9. [CrossRef]

6. Büchler MW, Friess H, Müller MW, Wheatley AM, Beger HG. Randomized trial of duodenum-preserving pancreatic head resection versus pylorus-preserving Whipple in chronicpancreatitis. Am J Surg 1995; 169: 65-9. [CrossRef]

7. Bachmann K, Kutup A, Mann O, Yekebas E, Izbicki JR. Surgical treatment in chronic pancreatitis timing and type of procedure. Best Pract Res Clin Gastroenterology 2010; 24: 299-310. [CrossRef]

8. Di Magno EP, Layer P, Clain JE. Chronicpancreatitis. In: Go VWL, Di Magno EO, Gardner JD (eds) Thepancreas, 1st edn. Raven, New York, 1993 pp 655-706.

9. Aaronson NK, Ahmedzai S, Bergman B, Bullinger M, Cull A, Duez NJ, et al. The European Organization for Researchand Treatment of Cancer QLQ-C30: A quality-of-life instrument for use in international clinical trials in oncology. J Natl Cancer Inst 1993; 85: 365-76. [CrossRef]

10. Sohn TA, Campbell KA, Pitt HA. Quality of life and long-term survival after surgery for chronic pancreatitis. J Gastrointest Surg 2000; 4: 355-64. [CrossRef]

11. Puestow CB, Gillesyby WJ. Retrograde surgical drainage of pancreas for chronic relapsing pancreatitis. AMA Arch Surg 1958; 76: 898-907. [CrossRef]

12. Partington PF, Rochelle RE. Modified Puestow procedure for retrograde drainage of the pancreatic duct. Ann Surg 1960; 152: 1037-43. [CrossRef]

13. Bradley EL III. Long-term results of pancreatojejunostomy in patients with chronic pancreatitis. Am J Surg 1987; 153: $207-$ 13. [CrossRef]

14. Taylor RH, Bagley FH, Braasch JW, Warren KW. Ductal drainage or resection for chronic pancreatitis. Am J Surg 1981; 141: 28-33. [CrossRef]

15. Jimenez R, Fernandez-del Castillo C, Rattner DW, Chang Y, Warshaw AL. Outcome of pancreaticoduodenectomy with pylorus preservation or with antrectomy in the treatment of chronic pancreatitis. Ann Surg 2000; 231: 293-300. [CrossRef]

16. Cooper MJ, Williamson RC, Benjamin IS, Carter DC, Cushieri A, Linehan IP, et al. Total pancreatectomy for chronic pancreatitis. Br J Surg 1987; 74: 912-5. [CrossRef]

17. Beger HG, Witte C, Krautzberger W, Bittner R. Experiences with duodenum-sparing pancreas head resection in chronic pancreatitis in German. Chirurg 1980; 51: 303-7.

18. Beger HG, Schlosser W, Friess HM, Büchler MW. Duodenumpreserving head resection in chronic pancreatitis changes the natural course of the disease: a single-center 26-year experience. Ann Surg 1999; 230: 512-9. [CrossRef]

19. Frey CF, Smith GJ. Description and rationale of a new operation for chronic pancreatitis. Pancreas 1987; 2: 701-7. [CrossRef]

20. Yekebas EF, Bogoevski D, Honarpisheh H, Çataldeğirmen G, Habermann CR, Seewald S, et al. Long-term follow-up in small duct chronic pancreatitis: A plea for extended drainage by "V shaped excision" of the anterior aspect of the pancreas. Ann Surg 2006; 244: 940-6. [CrossRef]

21. Klempa I, Spatny M, Menzel J, Baca I, Nustede R, Stöckmann F, et al. Pancreatic function and quality of life after resection of the head of the pancreas in chronic pancreatitis. A prospective, randomized comparative study after duodenum preserving resection of the head of the pancreas versus Whipple's operation. Chirurg 1995; 66: 350-9. 
22. Büchler MW, Friess H, Müller MW, Wheatley AM, Beger HG. Randomized trial of duodenum-preserving pancreatic head resection versus pylorus-preserving Whipple in chronic pancreatitis. Am J Surg 1995; 169: 65-9. [CrossRef]

23. Izbicki JR, Bloechle C, Broering DC, Knoefel WT, Kuechler T, Broelsch CE. Extended drainage versus resection in surgery for chronic pancreatitis: a prospective randomized trial comparing the longitudinal pancreaticojejunostomy combined with local pancreatic head excision with the pylorus-preserving pancreatoduodenectomy. Ann Surg 1998; 228: 771-9. [CrossRef]

24. Izbicki JR, Bloechle C, Knoefel WT, Kuechler T, Binmoeller KF, Broelsch CE. Duodenum-preserving resection of the head of the pancreas in chronic pancreatitis: a prospective, randomized trial. Ann Surg 1995; 221: 350-8. [CrossRef] 